\title{
Fixed Neck Position in Multilevel Cervical Posterior Decompression and Fusion to Reduce Postoperative Disturbances of Cervical Spine Function
}

\author{
Kazunari Takeuchi ${ }^{1)}$, Toru Yokoyama ${ }^{1)}$, Takuya Numasawa ${ }^{2)}$, Kan-ichiro Wada ${ }^{3)}$, Taito Itabashi ${ }^{4)}$, Yoshihito Yamasaki ${ }^{5)}$, \\ Hitoshi Kudo ${ }^{3)}$ and Seiya Ota ${ }^{3)}$ \\ 1) Department of Orthopedic Surgery, Odate Municipal General Hospital, Odate, Japan \\ 2) Department of Orthopedic Surgery, Hachinohe City Hospital, Hachinohe, Japan \\ 3) Department of Orthopaedic Surgery, Hirosaki University School of Medicine, Hirosaki, Japan \\ 4) Department of Orthopedic Surgery, Towada City Hospital, Towada, Japan \\ 5) Department of Orthopedic Surgery, Aomori City Hospital, Aomori, Japan
}

\begin{abstract}
:
Introduction: Difficulties with neck mobility often interfere with patients' activities of daily living (ADL) after cervical posterior spine surgery. The range of motion of the cervical spine decreases markedly after multilevel cervical posterior decompression and fusion (PDF). However, details regarding the limitations of cervical spine function due to postoperative reduced neck mobility after multilevel PDF are as yet unclarified. The present study aimed to clarify the quality of life and its related factors after PDF, and the optimal fixed neck position in multilevel PDF that minimizes the limitations of ADL accompanying markedly reduced postoperative neck mobility.

Methods: Limitations of ADL involving neck extension, rotation, and flexion were investigated in 32 consecutive patients who underwent C2-T1 PDF using the responses to the cervical spine function domain of the Japanese Orthopedic Association Cervical Myelopathy Evaluation Questionnaire (JOACMEQ). The EuroQol 5 Dimension, Japanese Orthopedic Association score, and five domains of the JOACMEQ were also investigated. We investigated the risk factors regarding the fixed neck position in PDF for the impossibility to perform ADL involving each of three movements using cut-off values obtained from receiver-operating characteristic curves.

Results: Postoperative comprehensive quality of life was significantly related to neurological improvements and to poor outcomes of cervical spine function after PDF. The significant risk factors for impossibility to perform ADL involving neck rotation were a $\mathrm{C} 2-\mathrm{C} 7$ lordotic angle $\geq 6^{\circ}(P=0.0057)$ or a proportion coefficient of $\mathrm{C} 2-\mathrm{T} 1$ tilt angle/C2-C7 lordotic angle $\leq 1.8(P=0.0024)$. There were no significant risk factors for impossibility to perform ADL involving neck extension or flexion.

Conclusions: The optimal fixed neck position in C2-T1 PDF to reduce postoperative limitations of ADL involving neck mobility is a $\mathrm{C} 2-\mathrm{C} 7$ lordotic angle of less than $6^{\circ}$, or a $\mathrm{C} 2-\mathrm{T} 1$ tilt angle $\left(^{\circ}\right)$ of greater than $1.8 \times$ the $\mathrm{C} 2-\mathrm{C} 7$ lordotic angle $\left({ }^{\circ}\right)$.
\end{abstract}

\section{Keywords:}

Posterior decompression and fusion, Instrumentation, Cervical spine function, Activity of daily living, Neck position, Alignment, Ossification of the posterior longitudinal ligament

Spine Surg Relat Res 2018; 2(4): 253-262 dx.doi.org/10.22603/ssrr.2017-0090

\section{Introduction}

Many clinical investigations have demonstrated satisfactory long-term neurological improvement following cervical laminoplasty ${ }^{1}$. However, cervical laminoplasty often results in restricted neck mobility, which interferes with patients' ADL. A previous study investigating limitations of ADL accompanying reduced neck mobility after laminoplasty re-

Corresponding author: Kazunari Takeuchi, t11161968@yahoo.co.jp

Received: November 30, 2017, Accepted: March 15, 2018, Advance Publication: April 27, 2018

Copyright (C) 2018 The Japanese Society for Spine Surgery and Related Research 
ported that the incidences of limitations of ADL according to postoperative reduced neck mobility (to any extent; mild, moderate, or severe) were rotation $(41 \%)$, extension $(34 \%)$, and flexion $(17 \%)^{2}$. Although items regarding ADL involving cervical spine function were not included in the previous Japanese Orthopedic Association (JOA) scoring system, these ADL have been included as the cervical spine function domain in the JOA Cervical Myelopathy Evaluation Questionnaire (JOACMEQ) that was developed in $2009^{3)}$.

Multilevel cervical posterior decompression and fusion (PDF) is commonly used to treat patients with cervical spondylotic myelopathy $(\mathrm{CSM})^{4)}$ or ossification of the posterior longitudinal ligament (OPLL) $)^{5,6)}$. It is thought that multilevel PDF more frequently results in reduced neck mobility that prevents patients from performing ADL compared with cervical laminoplasty. However, details regarding the limitations of ADL accompanying postoperative reduced neck mobility after PDF are as yet unclarified. Therefore, we retrospectively investigated the comprehensive quality of life (QOL) and its related factors, and the relationship between limitations of ADL involving neck mobility and fixed neck position in multilevel PDF to determine the optimal fixed neck position that reduces the limitations of ADL accompanying postoperative reduced neck mobility after PDF.

\section{Materials and Methods}

\section{Patients}

From March 2013 to January 2016, 32 consecutive patients (20 males and 12 females) with cervical myelopathy with K-line (-) OPLL in the neck-flexed position"), or CSM with a longitudinal distance index $(\mathrm{LDI})^{8)} \geq 5.0$ and K-line (-) alignment in the neck-flexed position underwent C2-T1 PDF and were included in the present study; these patients were designated as the PDF group. Conventional laminoplasty was performed in all patients with K-line (+) OPLL in the neck-neutral and neck-flexed positions, or CSM with a LDI $<5.0$, or CSM with a LDI $\geq 5.0$ and K-line (+) alignment in the neck-flexed position. No patient underwent anterior decompression and fusion. In the PDF group, OPLL was clinically evident in 23 patients, while CSM was present in nine. All 32 patients were investigated 1 year postoperatively, with a follow-up rate of $100 \%$. The average age at the time of surgery was 62 years (range, 34-87 years). Fiftyfour patients (32 males and 22 females) who underwent laminoplasty without instrumented fusion were included as a control group, which was designated as the LP group. In the LP group, OPLL was clinically evident in 17 patients, while CSM was present in 37. All 54 patients were investigated 1 year postoperatively, with a follow-up rate of $100 \%$. The average age at the time of surgery was 69 years (range, 27-86 years). All procedures performed in studies involving human participants were in accordance with the ethical standards of the institutional and/or national research committee and with the 1964 Helsinki declaration and its later amendments or comparable ethical standards.

\section{Operative Technique and Postoperative Treatment}

In both groups, laminectomy was performed at $\mathrm{C} 3$, with complete preservation of the semispinalis cervicis at $\mathrm{C}^{9}$. Spinous process-splitting laminoplasty was performed, with hydroxyapatite spinous process spacers (double-door type) placed at $\mathrm{C} 4-\mathrm{C} 7$ using a threadwire saw. In the PDF group, pedicle screws (PS) were inserted in the bilateral $\mathrm{C} 2, \mathrm{C} 7$ and $\mathrm{T} 1$ pedicles. The lateral mass screws at $\mathrm{C} 4-\mathrm{C} 6$ or the C5 PS were used as mid-cervical anchors (Fig. 1). We preserved the insertions at $\mathrm{C} 2$ of the oblique capitis inferior, semispinalis cervicis, and rectus capitis posterior major ${ }^{10}$. Local bone grafting was performed from $\mathrm{C} 2 / \mathrm{C} 3$ to $\mathrm{C} 7 / \mathrm{T} 1$ in all patients. Postoperative immobilization with a collar was not performed in any patient in either group.

\section{Radiologic Evaluation}

In both groups, all cervical spine radiographs were taken with the patient in standing position. The pre- and postoperative lordotic angle at $\mathrm{C} 2-\mathrm{C} 7$ was measured on a lateral radiograph of a neutral view of the cervical spine using the posterior tangents of the $\mathrm{C} 2$ and the $\mathrm{C} 7$ vertebral bodies (Fig. 2). The pre- and postoperative C2-T1 tilt angle ${ }^{11)}$ was measured on a lateral radiograph of a neutral view of the cervical spine as the angle between a vertical line and a line connecting the center of the pedicle of the $\mathrm{C} 2$ vertebral body and the posterosuperior aspect of the $\mathrm{T} 1$ vertebral body (Fig. 2). The pre- and postoperative O-C2 angle was also measured on a lateral radiograph of a neutral view of the cervical spine using the McGregor line and the posterior tangents of the $\mathrm{C} 2$ vertebral body (Fig. 2). The range of motion (ROM) at O-C7 was measured on lateral flexion and extension radiographs of the cervical spine using the McGregor line and the posterior tangent of the C7 vertebral body. All radiographs were measured using XTREX VIEW (J-MAC system, Sapporo, Japan), which was accurate to $0.01^{\circ}$.

\section{Measurements of Rotational ROM}

In both the groups, the pre- and postoperative rotational ROMs were measured on photographs. Patients were placed in a special wheelchair and secured in a seated position with belts. Cranial-view digital photographs were then taken with the patient wearing eyeglasses ${ }^{2,12}$. The photographs were scanned into a computer and we measured the ROM using the line between the centers of the round seals that we had put on the bilateral acromions and the line between the centers of the round seals that we had put at the bilateral corners of the frame of the eyeglasses (Fig. 3) using an image processing software (Image $\mathrm{J}$; US National Institutes of Health, Bethesda, MD, USA), which was accurate to $0.01^{\circ}$. The intraclass correlation coefficient for measurements of rotational ROM was 0.990, indicating good intraobserver reliability. 


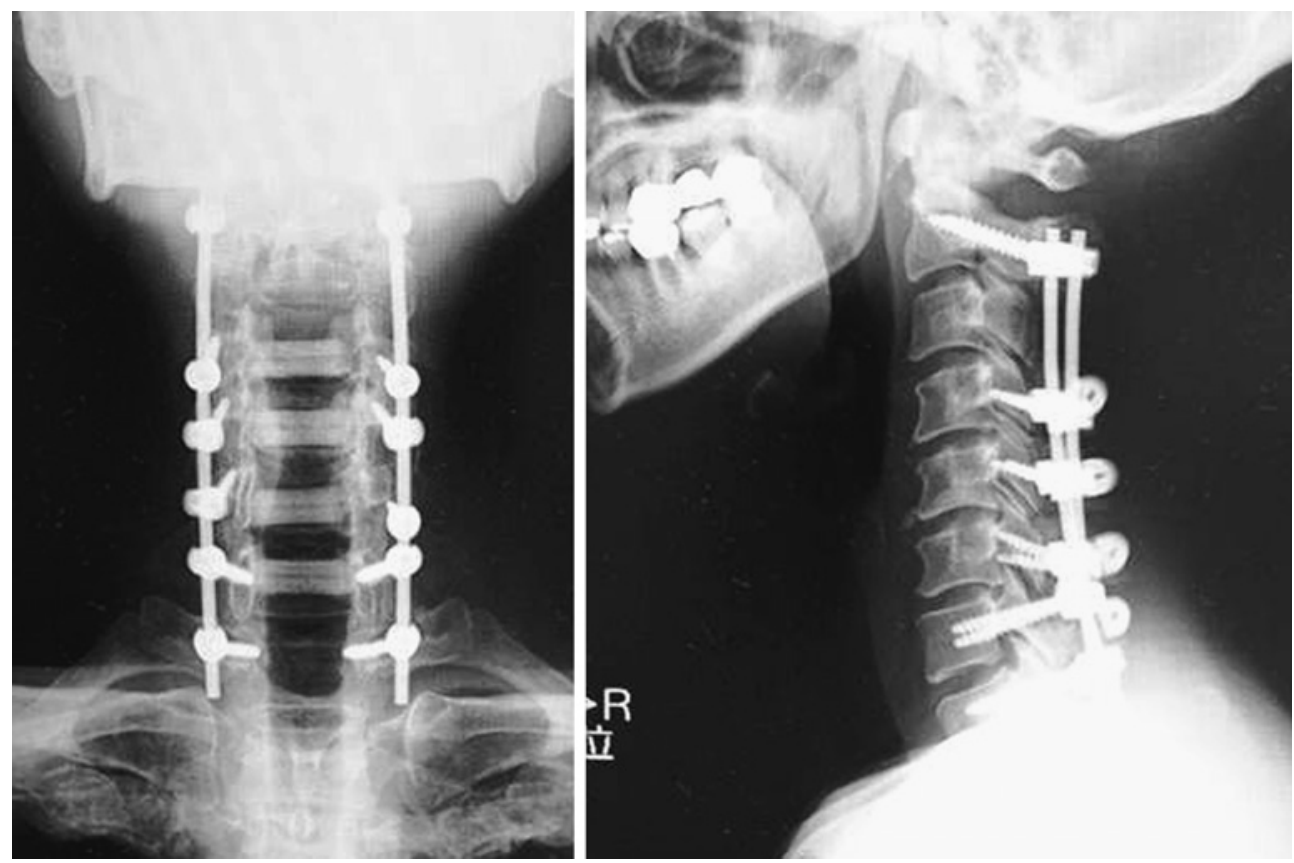

Figure 1. Cervical spine radiography demonstrating the C2-T1 posterior decompression and fusion procedure performed in our institution. Left image: anteroposterior view. Right image: lateral view.
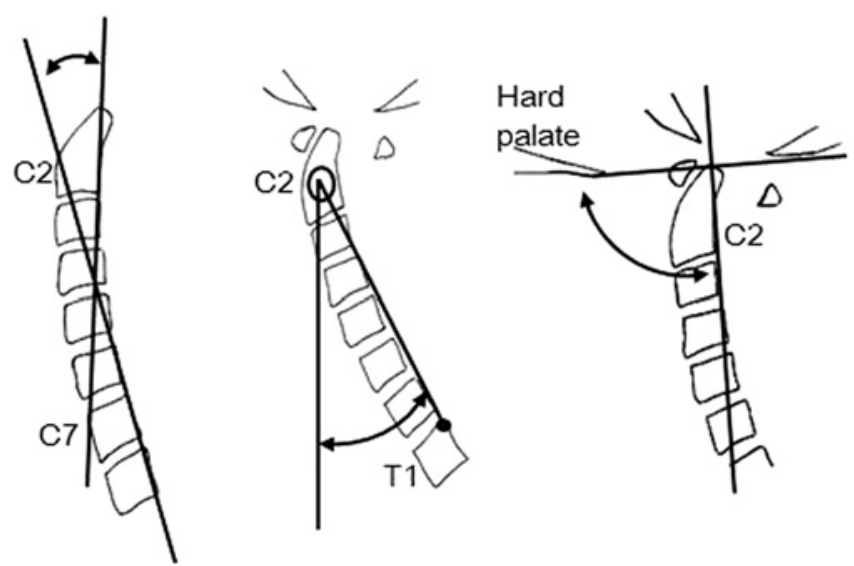

Figure 2. Measurements of radiologic evaluations. Left image: C2-C7 lordotic angle. Middle image: C2-T1 tilt angle. Right image: $\mathrm{O}-\mathrm{C} 2$ angle.

\section{Evaluation of Health-Related QOL and Neurological Find- ings}

In the PDF group, the pre- and postoperative EuroQol 5 Dimension (EQ-5D) ${ }^{13)}$ were examined to evaluate the healthrelated QOL. The descriptive system comprises five dimensions: mobility, self-care, usual activities, pain/discomfort, and anxiety/depression. The pre- and postoperative JOA scores and the recovery rate of the JOA score were investigated in all patients. The recovery rate of the JOA score was calculated as follows: recovery rate $(\%)=$ (postoperative JOA score - preoperative JOA score) / (17 - preoperative JOA score $) \times 100$. The pre- and postoperative JOACMEQ ${ }^{3)}$ findings were investigated in all patients. Improvements in the five individual JOACMEQ domains $(\mathrm{Q} 1$ : cervical spine function; Q2: upper extremity function; Q3: lower extremity function; Q4: bladder function; and Q5: QOL) were investigated. According to the JOACMEQ exclusion criteria, patients whose pre- and postoperative scores were $\geq 90$ points were excluded from the analysis.

\section{Evaluation of ADL Involving Neck Mobility}

In both groups, the frequencies of the pre- and postoperative limitations of ADL involving each of the following neck movements were investigated using four items from Question 1 (cervical spine function domain) of the JOACMEQ: extension (Q1-1 and/or Q1-2), rotation (Q1-3), and flexion (Q1-4) (Table 1) ${ }^{3}$. Each ADL was assessed as possible or impossible using the patient-reported questionnaire.

\section{Statistical Analysis}

The Wilcoxon's signed-rank test, the paired $t$-test, or the Student's $t$-test was applied in the statistical analyses. The cut-off values for postoperative inability to perform ADL involving neck movements in the three directions were assessed using receiver-operating characteristic (ROC) curves for the following three factors: postoperative $\mathrm{C} 2-\mathrm{C} 7$ lordotic angle, C2-T1 tilt angle, and proportion coefficient of C2-T1 tilt angle/C2-C7 lordotic angle. Then, the risk factors that were set by each cut-off value for postoperative inability to perform ADL involving neck movements in the three directions were statistically analyzed using the chi-squared test. Differences with a $P$ value of $<0.05$ were considered statistically significant. 

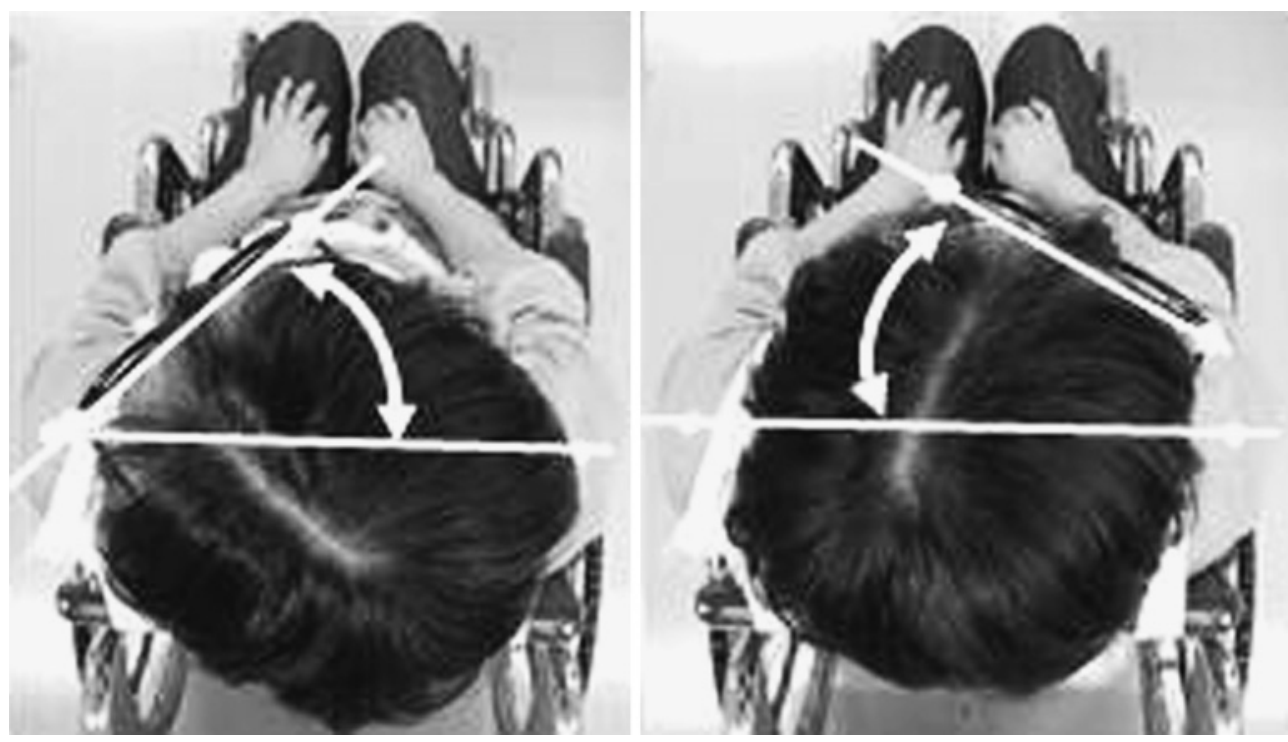

Figure 3. Rotational range of motion (ROM) measurement. Patients were seated in a wheelchair for cranial-view photography. Rotational $\mathrm{ROM}=$ left rotation angle+right rotation angle.

Table 1. Cervical Spine Function Questions in the JOACMEQ.

\begin{tabular}{cl}
\hline \multicolumn{1}{c}{ Movement } & \multicolumn{1}{c}{ Activities of Daily Living } \\
\hline Q1-1: Extension & While in the sitting position, can you look up at the ceiling by moving your head directly backward? \\
Q1-2: Extension & Can you drink a glass of water in one gulp? \\
Q1-3: Rotation & While in the sitting position, can you turn your head toward the person who is seated behind you and \\
speak to him/her while looking at him/her in the face?
\end{tabular}

JOACMEQ: Japanese Orthopedic Association Cervical Myelopathy Evaluation Questionnaire

\section{Results}

\section{Radiographic Evaluations, Rotational ROM, and Distribu- tion of the Possibility or Impossibility of ADL Involving Neck Movements}

The pre- and postoperative radiologic parameters, rotational ROM, and distribution of the possibility or impossibility of ADL involving neck movements in both groups are shown in Table 2. The mean postoperative $\mathrm{C} 2-\mathrm{C} 7$ lordotic angle, O-C7 ROM, and rotational ROM in the PDF group were significantly smaller than those in the LP group $(P=$ $0.0010, P<0.0001$, and $P<0.0001$, respectively). The mean postoperative $\mathrm{C} 2-\mathrm{T} 1$ tilt angle and $\mathrm{O}-\mathrm{C} 2$ angle in the PDF group were significantly larger than those in the LP group $(P=0.0138$ and $P=0.0005$, respectively).

Regarding alignments in the PDF group, the mean postoperative C2-T1 tilt angle was significantly larger than the mean preoperative $\mathrm{C} 2$-T1 tilt angle $(P=0.0163)$, and the mean postoperative $\mathrm{O}-\mathrm{C} 2$ angle was significantly larger than the mean preoperative $\mathrm{O}-\mathrm{C} 2$ angle $(P=0.0047)$. There was no correlation between the postoperative $\mathrm{C} 2-\mathrm{C} 7$ lordotic angle and the postoperative $\mathrm{C} 2-\mathrm{T} 1$ tilt angle. Although there was a tendency toward a negative correlation between the postoperative $\mathrm{C} 2-\mathrm{C} 7$ lordotic and $\mathrm{O}-\mathrm{C} 2$ angles, the difference was not statistically significant $(P=0.0774)$. There was a significant positive correlation between the postoperative $\mathrm{C} 2-\mathrm{T} 1$ tilt angle and the postoperative $\mathrm{O}-\mathrm{C} 2$ angle $(P=$ $0.0152, r=0.422$ ).

Regarding ROM in the PDF group, the mean postoperative O-C7 ROM was significantly smaller than the mean preoperative O-C7 ROM $(P<0.0001)$, and the mean postoperative rotational ROM was significantly smaller than the mean preoperative rotational ROM $(P<0.0001)$. There was no correlation between the postoperative O-C7 ROM and the $\mathrm{C} 2-\mathrm{C} 7$ lordotic angle or the $\mathrm{C} 2-\mathrm{T} 1$ tilt angle. Although there was no correlation between the postoperative rotational $\mathrm{ROM}$ and the $\mathrm{C} 2-\mathrm{C} 7$ lordotic angle or the C2-T1 tilt angle, there was a significant positive correlation between the postoperative rotational ROM and the postoperative O-C2 angle $(P=0.0137, r=0.428)$.

The pre- and postoperative distributions of the ability to perform ADL involving neck mobility using the JOACMEQ Q-1 domain did not differ between groups. There was no correlation between the postoperative ability to perform ADL involving neck movements in each of the three directions and the postoperative O-C7 ROM. Although there was a tendency for the mean postoperative rotational ROM in patients for whom ADL involving neck rotation were impossible $\left(71.9^{\circ}\right)$ to be smaller than that in patients for whom these ADL were possible $\left(82.9^{\circ}\right)$, the difference was not statistically significant $(P=0.0591)$. Fig. 4 shows the distribu- 
Table 2. Comparison of Alignments, ROM of the Cervical Spine, and ADL Accompanying Neck Mobility between Both the Groups.

\begin{tabular}{|c|c|c|c|}
\hline & PDF group (n=32) & LP group $(n=54)$ & $P$ value \\
\hline \multicolumn{4}{|l|}{ Preoperative } \\
\hline $\mathrm{C} 2-\mathrm{C} 7$ lordotic angle $\left({ }^{\circ}\right)$ & $7.3 \pm 12.7$ & $16.7 \pm 12.9$ & 0.0014 \\
\hline $\mathrm{C} 2-\mathrm{T} 1$ tilt angle $\left(^{\circ}\right)$ & $18.0 \pm 8.9$ & $14.7 \pm 6.7$ & 0.0588 \\
\hline $\mathrm{O}-\mathrm{C} 2$ angle $\left({ }^{\circ}\right)$ & $102.2 \pm 7.3$ & $96.8 \pm 8.5$ & 0.0057 \\
\hline $\mathrm{O}-\mathrm{C} 7 \mathrm{ROM}\left({ }^{\circ}\right)$ & $63.8 \pm 15.4$ & $68.5 \pm 13.1$ & 0.1361 \\
\hline Rotational ROM $\left(^{\circ}\right)$ & $113.1 \pm 16.6$ & $117.7 \pm 16.4$ & 0.2469 \\
\hline \multirow[t]{2}{*}{ Extension ADL } & Possible: 30 (94\%) & Possible: 43 (80\%) & 0.1455 \\
\hline & Impossible: $2(6 \%)$ & Impossible: $11(20 \%)$ & \\
\hline \multirow[t]{2}{*}{ Rotation ADL } & Possible: 24 (75\%) & Possible: 40 (74\%) & $>0.999$ \\
\hline & Impossible: 8 (25\%) & Impossible: 14 (26\%) & \\
\hline \multirow[t]{2}{*}{ Flexion ADL } & Possible: 30 (94\%) & Possible: 44 (81\%) & 0.2058 \\
\hline & Impossible: $2(6 \%)$ & Impossible: $10(19 \%)$ & \\
\hline \multicolumn{4}{|l|}{1 year postoperative } \\
\hline $\mathrm{C} 2-\mathrm{C} 7$ lordotic angle $\left(^{\circ}\right)$ & $11.5 \pm 12.8$ & $20.2 \pm 12.8$ & 0.0010 \\
\hline C2-T1 tilt angle $\left(^{\circ}\right)$ & $21.1 \pm 9.5$ & $16.3 \pm 7.9$ & 0.0138 \\
\hline $\mathrm{O}-\mathrm{C} 2$ angle $\left({ }^{\circ}\right)$ & $105.1 \pm 7.8$ & $98.3 \pm 8.6$ & 0.0005 \\
\hline $\mathrm{O}-\mathrm{C} 7 \mathrm{ROM}\left({ }^{\circ}\right)$ & $34.9 \pm 6.5$ & $54.2 \pm 10.5$ & $<0.0001$ \\
\hline Rotational ROM $\left(^{\circ}\right)$ & $78.4 \pm 16.4$ & $100.3 \pm 14.1$ & $<0.0001$ \\
\hline \multirow[t]{2}{*}{ Extension ADL } & Possible: $23(72 \%)$ & Possible: 42 (78\%) & 0.7216 \\
\hline & Impossible: $9(28 \%)$ & Impossible: $12(22 \%)$ & \\
\hline \multirow[t]{2}{*}{ Rotation ADL } & Possible: $19(59 \%)$ & Possible: $36(67 \%)$ & 0.6538 \\
\hline & Impossible: $13(41 \%)$ & Impossible: 18 (33\%) & \\
\hline \multirow[t]{2}{*}{ Flexion ADL } & Possible: $28(87 \%)$ & Possible: $45(83 \%)$ & 0.8337 \\
\hline & Impossible: $4(13 \%)$ & Impossible: 9 (17\%) & \\
\hline
\end{tabular}

ADL data are presented as number of patients

PDF: posterior decompression and fusion; LP: laminoplasty; ROM: range of motion; ADL: activities of daily living
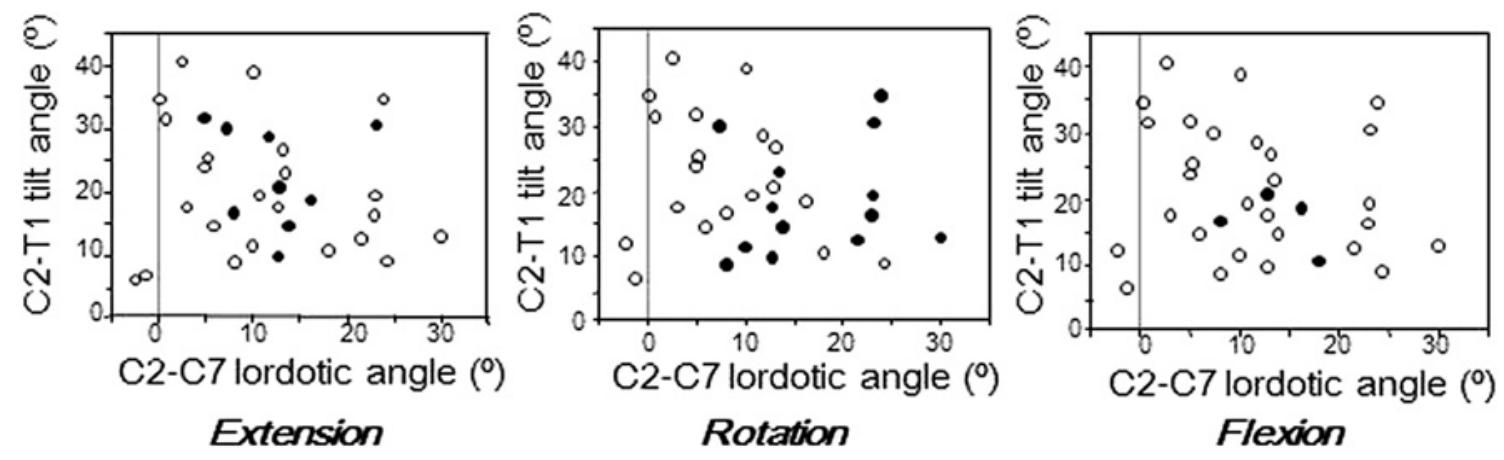

Figure 4. Distribution of limitations of activities of daily living (ADL) involving each neck movement. Left image: extension. Middle image: rotation. Right image: flexion. Black circles indicate patients for whom ADL were impossible; white circles indicate patients for whom ADL were possible.

tion of postoperative ADL involving neck movements in the three directions according to the postoperative C2-C7 lordotic angle and the postoperative C2-T1 tilt angle in the PDF group.

\section{Pre- and Postoperative EuroQol 5 Dimension and Neuro- logical Evaluations in the PDF Group}

The mean pre- and postoperative EQ-5D ${ }^{13)}$ and JOA score outcomes in the PDF group are shown in Table 3. The preoperative EQ-5D and JOA score outcomes were significantly improved postoperatively $(P=0.0305$ and $P<0.0001$, respectively), and the mean recovery rate of the JOA score was $41.4 \%$. The mean pre- and postoperative JOACMEQ ${ }^{3)}$ outcomes in the PDF group are shown in Table 4. Although the rates of a successful outcome (success rate) for Q1: cervical spine function (15.6\%) and Q5: QOL (15.6\%) tended to be lower than those for Q2: upper extremity function (34.8\%), Q3: lower extremity function (36\%), and Q4: bladder function $(38.5 \%)$, these differences were not statistically significant. Twelve $(86 \%)$ of 14 patients whose outcomes of 
Table 3. Pre- and Postoperative EQ-5D and JOA Score Outcomes in the PDF Group $(n=32)$.

\begin{tabular}{lccr}
\hline & Preoperative & 1 year postoperative & $P$ value \\
\hline EQ-5D & $0.502 \pm 0.316$ & $0.667 \pm 0.259$ & 0.0305 \\
JOA score & $10.8 \pm 12.7$ & $13.3 \pm 2.6$ & $<0.0001$ \\
& & Recovery rate: $41.4 \% \pm 35.3 \%$ &
\end{tabular}

EQ-5D: EuroQol 5 Dimension; JOA: Japanese Orthopaedic Association; PDF: posterior decompression and fusion

Table 4. Pre- and Postoperative JOACMEQ Outcomes in the PDF Group ( $n=32)$.

\begin{tabular}{llccccc}
\hline & & $\begin{array}{c}\text { Cervical spine } \\
\text { function }\end{array}$ & $\begin{array}{c}\text { Upper extremity } \\
\text { function }\end{array}$ & $\begin{array}{c}\text { Lower extremity } \\
\text { function }\end{array}$ & Bladder function & $\begin{array}{c}\text { Quality of } \\
\text { life }\end{array}$ \\
\hline Preoperative & & $97.0 \pm 32.0$ & $83.2 \pm 21.2$ & $67.1 \pm 29.5$ & $75.9 \pm 20.4$ & $97.0 \pm 32.0$ \\
1 year postoperative & & $50.3 \pm 23.0$ & $84.0 \pm 16.8$ & $76.1 \pm 24.1$ & $81.9 \pm 19.2$ & $50.3 \pm 23.0$ \\
& Excluded & 0 & 9 & 7 & 6 & 0 \\
& Effective & 5 & 8 & 9 & 10 & 5 \\
Success rate & Not effective (Deteriorated) & $27(24)$ & $15(9)$ & $16(8)$ & $16(7)$ & $27(14)$ \\
& & $15.6 \%$ & $34.8 \%$ & $36 \%$ & $38.5 \%$ & $15.6 \%$ \\
\hline
\end{tabular}

Data are presented as number of patients

JOACMEQ: Japanese Orthopedic Association Cervical Myelopathy Evaluation Questionnaire; PDF: posterior decompression and fusion

Table 5. Relationships between the Postoperative EQ-5D and Postoperative Factors in the PDF Group.

\begin{tabular}{lr}
\hline \multicolumn{1}{c}{ Factor } & $P$ value \\
\hline Postoperative C2-C7 lordotic angle $\left(^{\circ}\right)$ & 0.7142 \\
Postoperative C2-T1 tilt angle $\left({ }^{\circ}\right)$ & 0.8989 \\
Postoperative O-C7 ROM $\left(^{\circ}\right)$ & 0.8470 \\
Postoperative rotational ROM $\left({ }^{\circ}\right)$ & 0.8151 \\
Recovery rate of JOA score & 0.0310 \\
Postoperative JOACMEQ Q1 (Cervical spine function) & 0.9878 \\
Postoperative JOACMEQ Q2 (Upper extremity function) & $<0.0001$ \\
Postoperative JOACMEQ Q3 (Lower extremity function) & 0.0103 \\
Postoperative JOACMEQ Q4 (Bladder function) & 0.0536 \\
Postoperative JOACMEQ Q5 (Quality of life) & 0.0269 \\
\hline
\end{tabular}

EQ-5D: EuroQol 5 Dimension; PDF: posterior decompression and fusion; JOA: Japanese Orthopaedic Association; ROM: range of motion; JOACMEQ: Japanese Orthopaedic Association Cervical Myelopathy Evaluation Questionnaire

the JOACMEQ Q5 QOL domain were deteriorated postoperatively also showed a decrease in the JOACMEQ O1 cervical spine function domain postoperatively. Correlations between the mean postoperative EQ-5D and the other factors in the PDF group are shown in Table 5; the significantly correlated factors were the mean recovery rate of the JOA score $(P=0.0310, r=0.380)$ and the mean postoperative JOACMEQ outcomes for Q2 $(P<0.0001, r=0.626)$, Q3 $(P=0.0103, r=0.443)$, and Q5 $(P=0.0269, r=0.389)$. Correlations between the outcome of the JOACMEQ Q5 QOL domain and the outcomes of the other JOACMEQ domains in the PDF group are shown in Table 6. The outcome of the JOACMEQ Q5 QOL domain was significantly correlated with the outcome of the Q1 cervical spine function do-
Table 6. Relationships between the Outcomes of JOACMQ Q5 (QOL) Domain and Other Domains in the PDF Group ( $n=32)$.

\begin{tabular}{lccc}
\hline & Q1: Effective & Q1: Not effective & $P$ value \\
\hline Q5: Effective & 4 & 4 & 0.0114 \\
Q5: Not effective & 1 & 23 & \\
\hline \multicolumn{4}{c}{} \\
\hline Q5: Effective & 4 & 2 & 0.1526 \\
Q5: Not effective & 4 & 13 & \\
\hline
\end{tabular}

\begin{tabular}{lccc}
\hline & Q3: Effective & Q3: Not effective & $P$ value \\
\hline Q5: Effective & 3 & 4 & $>0.999$ \\
Q5: Not effective & 6 & 12 & \\
\hline & & & \\
\hline & Q4: Effective & Q4: Not effective & $P$ value \\
\hline Q5: Effective & 3 & 3 & 0.8540 \\
Q5: Not effective & 7 & 13 & \\
\hline
\end{tabular}

Data are presented as number of patients

JOACMEQ: Japanese Orthopaedic Association Cervical Myelopathy Evaluation Questionnaire; QOL: quality of life; PDF: posterior decompression and fusion

main $(P=0.0114)$.

Cut-Off Values of the C2-C7 Lordotic Angle, C2-T1 Tilt Angle, and the Proportion Coefficient of the C2-T1 Tilt Angle/C2-C7 Lordotic Angle for Each ADL Involving Neck Mobility

Table 7 summarizes the cut-off values and areas under the ROC curves (AUC) for postoperative C2-C7 lordotic angle, $\mathrm{C} 2-\mathrm{T} 1$ tilt angle, and the proportion coefficient of C2-T1 tilt 
Table 7. Cut-off Values and AUC for Postoperative Ability to Perform ADL Involving Neck Movements in the Three Directions.

\begin{tabular}{lcccc}
\hline & Cut-off value & AUC $(95 \%$ CI $)$ & Sensitivity & Specificity \\
\hline Extension & & & & \\
C2-C7 lordotic angle & $5.9^{\circ}$ & $0.572(0.374,0.771)$ & 0.391 & 0.889 \\
C2-T1 tilt angle & $14.7^{\circ}$ & $0.604(0.394,0.814)$ & 0.391 & 0.889 \\
C2-T1 tilt angle/C2-C7 lordotic angle & 0.7 & $0.556(0.357,0.754)$ & 0.304 & 1.000 \\
\hline Rotation & & & & \\
C2-C7 lordotic angle & $5.9^{\circ}$ & $0.814(0.667,0.961)$ & 0.526 & 1.000 \\
C2-T1 tilt angle & $17.8^{\circ}$ & $0.623(0.424,0.823)$ & 0.684 & 0.615 \\
C2-T1 tilt angle/C2-C7 lordotic angle & 1.8 & $0.741(0.558,0.924)$ & 0.684 & 0.923 \\
\hline Flexion & & & & \\
C2-C7 lordotic angle & $10.0^{\circ}$ & $0.634(0.424,0.844)$ & 0.500 & 0.750 \\
C2-T1 tilt angle & $23.1^{\circ}$ & $0.616(0.405,0.828)$ & 0.464 & 1.000 \\
C2-T1 tilt angle/C2-C7 lordotic angle & 2.5 & $0.589(0.370,0.808)$ & 0.393 & 1.000 \\
\hline
\end{tabular}

AUC: area under the receiver-operator characteristic curves; ADL: activities of daily living; CI: confidence interval
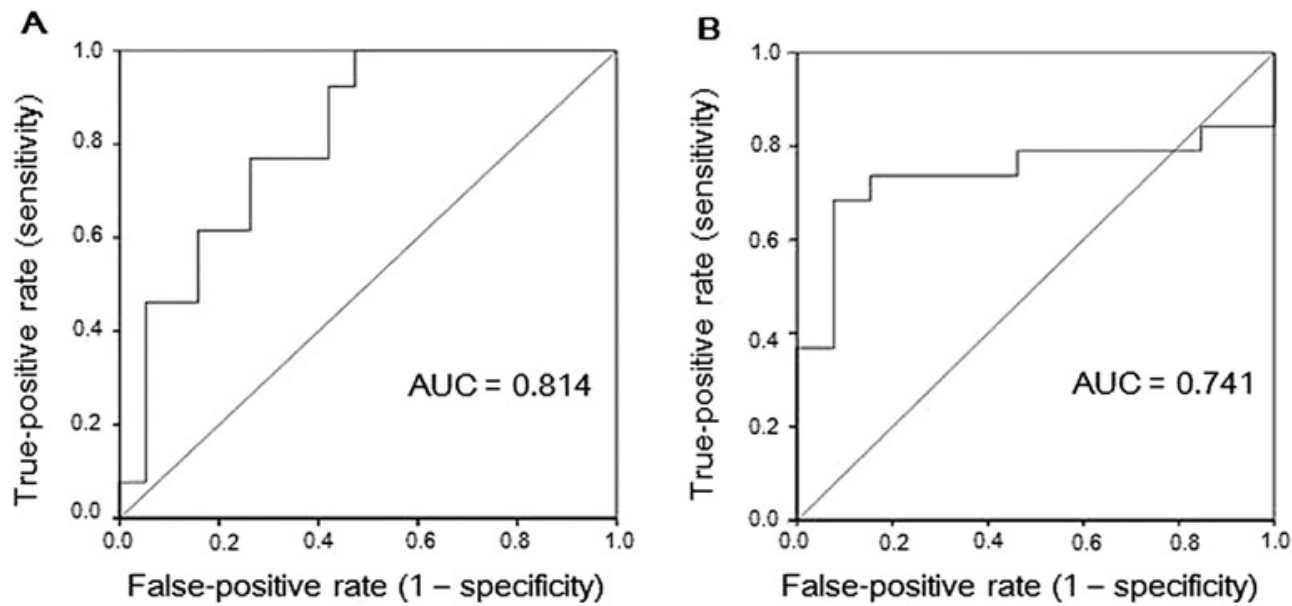

Figure 5. Receiver-operating characteristic curves. A: C2-C7 lordotic angle for activities of daily living (ADL) involving neck rotation. B: Proportion coefficient of C2-T1 tilt angle/C2-C7 lordotic angle for ADL involving neck rotation. AUC, area under the curve.

angle/C2-C7 lordotic angle for postoperative ability to perform ADL involving neck movements in the three directions. Only the cut-off values for the $\mathrm{C} 2-\mathrm{C} 7$ lordotic angle and the proportion coefficient of C2-T1 tilt angle/C2-C7 lordotic angle for ADL involving neck rotation were assessed as moderately predictive $(0.70-0.90)$ based on the AUC results $^{14)}$, while all other values were less predictive $(0.50$ $0.70)^{9)}$. ROC curves of the C2-C7 lordotic angle and the proportion coefficient of the $\mathrm{C} 2-\mathrm{T} 1$ tilt angle/C2-C7 lordotic angle for ADL involving neck rotation are shown in Fig. 5. The relationships of each risk factor with the postoperative inability to perform ADL involving neck movements in the three directions are shown in Table 8 . The significant risk factors for the inability to perform ADL involving neck rotation were a $\mathrm{C} 2-\mathrm{C} 7$ lordotic angle $\geq 6^{\circ}(P=0.0057)$ and a proportion coefficient of C2-T1 tilt angle/C2-C7 lordotic angle $\leq 1.8(P=0.0024)$. There were no significant risk factors for postoperative inability to perform ADL involving neck extension or flexion.

\section{Discussion}

It can be difficult to perform multilevel anterior decompression and fusion for multilevel compressive myelopathy due to OPLL or cervical spondylosis because of the high risk of severe complications such as cord injury ${ }^{15)}$, acute airway obstruction due to retropharyngeal hematoma ${ }^{16)}$, pulmonary complications ${ }^{17)}$, pseudarthrosis of the graft bone ${ }^{18}$, pharyngo-esophageal perforation ${ }^{19)}$, dysphagia ${ }^{17)}$, and dysphonia $^{20)}$. Although posterior fusion using PS also has several complications such as injuries of the cervical $\operatorname{cord}^{15)}$ or the vertebral artery ${ }^{21)}$ due to perforation by the PS, the accuracy of PS positioning was improved by the development of the insertion technique using several types of navigation systems ${ }^{22,23)}$. Multilevel PDF is commonly used to treat OPLL or $\mathrm{CSM}^{4-6)}$, and PDF using PS is also reportedly effective for correction of malalignment of the cervical spine ${ }^{24)}$.

In recent years, many risk factors for poor neurological outcome after cervical laminoplasty have been reported. Fuji- 
Table 8. Relationships between Each Risk Factor and Postoperative Inability to Perform ADL Involving Neck Movements in the Three Directions.

\begin{tabular}{lcc}
\hline & Risk factor & $P$ value \\
\hline Extension & & \\
C2-C7 lordotic angle & $\geq 6^{\circ}$ & 0.2656 \\
C2-T1 tilt angle & $\geq 15^{\circ}$ & 0.2656 \\
C2-T1 tilt angle/C2-C7 lordotic angle & $\geq 0.7$ & 0.1624 \\
\hline Rotation & & \\
C2-C7 lordotic angle & $\geq 6^{\circ}$ & 0.0057 \\
C2-T1 tilt angle & $\leq 18^{\circ}$ & 0.1885 \\
C2-T1 tilt angle/C2-C7 lordotic angle & $\leq 1.8$ & 0.0024 \\
\hline Flexion & & \\
C2-C7 lordotic angle & $\geq 10^{\circ}$ & 0.7876 \\
C2-T1 tilt angle & $\leq 23^{\circ}$ & 0.2208 \\
C2-T1 tilt angle/C2-C7 lordotic angle & $\leq 2.5$ & 0.3478 \\
\hline
\end{tabular}

ADL: activities of daily living

yoshi et $a l .{ }^{25)}$ examined patients with OPLL after en bloc laminoplasty $(n=19)$ and after $\operatorname{PDF}(n=8)$, reporting a mean recovery rate of $13.9 \%$ in the $\mathrm{K}$-line (-) group and $66.0 \%$ in the K-line (+) group. Furthermore, Takeuchi et al. ${ }^{7}$ examined 41 patients with OPLL who underwent laminoplasty, and reported that the JOA score recovery of patients with K-line (-) OPLL in the neck-flexed position was significantly lesser than that of patients with K-line (+) OPLL in the same position. Chiba et al. ${ }^{8)}$ examined 70 patients with postoperative cervical malalignment after expansive open-door laminoplasty for cervical myelopathy, and defined the LDI as the length of a straight line between the posteroinferior edges of $\mathrm{C} 2$ and $\mathrm{C} 7$ divided by the anteroposterior diameter of $\mathrm{C} 4$; this was measured on lateral neutral radiographs at the final follow-up. Patients with CSM had a smaller LDI and better surgical outcome than those with OPLL, and the LDI was negatively correlated with percentage of recovery, indicating that the longitudinal distance of the cervical spine may impact the surgical outcome of laminoplasty. Therefore, from March 2013, we performed C 2-T1 PDF in patients with cervical myelopathy with K-line (-) OPLL in the neck-flexed position ${ }^{7)}$, or CSM with a $\mathrm{LDI}^{8)}$ $\geq 5.0$ and $\mathrm{K}$-line (-) alignment in the neck-flexed position. Regarding postoperative neurological improvement for those with K-line (-) OPLL, Koda et $a l^{6}{ }^{6}$ reported that the JOA score recovery rate in the PDF group was significantly higher than that in the laminoplasty group. As there are no studies reporting postoperative neurological evaluations after PDF for patients with cervical myelopathy with K-line (-) OPLL in the neck-flexed position, or CSM with a LDI $\geq 5.0$ and K-line (-) alignment in the neck-flexed position, further studies are required to investigate the neurological outcomes after PDF compared with laminoplasty in a greater number of patients with these surgical indications.

It is as yet unclear whether multilevel PDF provides adequate fixed alignment of the cervical spine. In the present

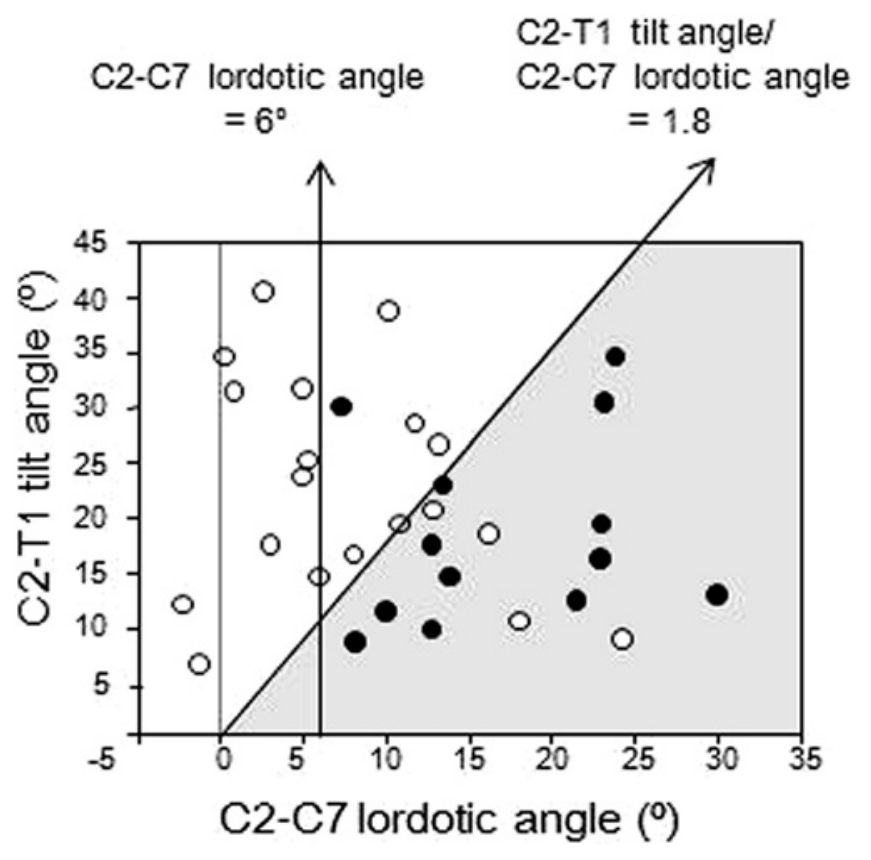

Figure 6. Optimal fixed neck position in $\mathrm{C} 2-\mathrm{T} 1$ posterior decompression and fusion (white area). Black circles indicate patients for whom activities of daily living (ADL) involving neck rotation were impossible; white circles indicate patients for whom ADL involving neck rotation were possible.

study, there were no significant risk factors for postoperative inability to perform ADL involving neck extension or flexion; however, the significant risk factors for postoperative inability to perform ADL involving neck rotation were a C2C7 lordotic angle $\geq 6^{\circ}$ or a proportion coefficient of C2-T1 tilt angle/C2-C7 lordotic angle $\leq 1.8$. Hence, to prevent postoperative inability to perform ADL involving neck rotation, the $\mathrm{C} 2-\mathrm{C} 7$ lordotic angle should be less than $6^{\circ}$, or the proportion coefficient of the $\mathrm{C} 2-\mathrm{T} 1$ tilt angle/C2-C7 lordotic angle should be greater than 1.8 (Fig. 6). The present results suggest that when these fixed positions were present, the incidence of postoperative inability to perform ADL involving neck rotation increased. However, the decrease in limitations of ADL accompanying postoperative reduced neck mobility may improve the comprehensive QOL after PDF, as a poor outcome in the JOACMEQ Q1 cervical spine function domain was significantly related to a poor outcome in the JOACMEQ Q5 QOL domain.

The position of the head after cervical spine surgery is often evaluated using the $\mathrm{C} 2-\mathrm{C} 7$ sagittal vertical axis, which is the horizontal offset distance between the $\mathrm{C} 2$ plumb line and the $\mathrm{C} 7$ vertebral body. However, the $\mathrm{C} 2-\mathrm{C} 7$ sagittal vertical axis may be influenced by the amplification of the intraoperative fluoroscopy photographs or roentgen photographs and/or the differences in the build of patients. Therefore, we measured the C2-T1 tilt angle, as it is not influenced by these factors; this follows the method of Patwardhan et al. ${ }^{11}$. We consider that the $\mathrm{C} 2-\mathrm{C} 7$ lordotic angle and the C2-T1 tilt angle are the only factors that surgeons can manipulate artificially intraoperatively. Regarding the caudal 
fixation level in multilevel PDF, Schroeder et al. ${ }^{26)}$ examined the revision rates of 219 patients after PDF and reported that multilevel PDF should be extended to T1, as stopping a long construct at $\mathrm{C} 7$ increases the rate of revision. The position of the head can be controlled using the C2-T1 tilt angle by extending the caudal fixation level to $\mathrm{T} 1$, as is done in $\mathrm{C}$ 2-T1 PDF performed in our institution. To prevent postoperative inability to perform ADL involving neck rotation, operators should be able to create a $\mathrm{C} 2-\mathrm{C} 7$ lordotic angle of less than $6^{\circ}$, or a C2-T1 tilt angle $\left(^{\circ}\right)$ of greater than $1.8 \times$ the $\mathrm{C} 2-\mathrm{C} 7$ lordotic angle $\left({ }^{\circ}\right)$ while going up and down using cranial stabilization equipment such as a MAYFIELD headrest system if the intraoperative $\mathrm{C} 2-\mathrm{C} 7$ lordotic angle is greater than $6^{\circ}$ on intraoperative fluoroscopy photographs or roentgen photographs.

There was a significant positive correlation between the postoperative $\mathrm{C} 2-\mathrm{T} 1$ tilt angle and the postoperative O-C2 angle, and a tendency toward a negative correlation between the postoperative $\mathrm{C} 2-\mathrm{C} 7$ lordotic angle and the postoperative $\mathrm{O}-\mathrm{C} 2$ angle. Furthermore, there was a significant positive correlation between the postoperative $\mathrm{O}-\mathrm{C} 2$ angle and the postoperative rotational ROM. Therefore, the patients belonging to the white area of Fig. 6 had a larger O-C2 angle (i.e., more extension alignment at $\mathrm{O}-\mathrm{C} 2$ ) and larger postoperative rotational ROM than the patients belonging to the gray area. Actually, in the present study, there was a tendency for the mean postoperative rotational ROM in patients for whom ADL involving neck rotation were possible $\left(82.9^{\circ}\right)$ to be larger than that in patients for whom ADL were impossible $\left(71.9^{\circ}\right)$. The motion in the upper cervical spine, especially in the atlantoaxial joint, is mainly limited by the alar ligaments, which connect the dens axis, the occipital condyles, and the anterior arch of the axis with inelastic collagen fibers ${ }^{27}$. A posterior inclination of the alar ligaments reportedly induces coupled extension in combination with lateral bending during axial rotation ${ }^{28)}$. The largest main rotation at $\mathrm{C} 1-\mathrm{C} 2$ and the largest coupled extension at $\mathrm{O}-\mathrm{C} 1$ were also reported using axial loading ${ }^{27)}$. Therefore, rotational movement becomes easier due to extension alignment at $\mathrm{O}-\mathrm{C} 2$, as the strain of the alar ligaments may relax. The patients belonging to the white area in Fig. 6 might be able to rotate the head more easily because of their extension alignment at $\mathrm{O}-\mathrm{C} 2$. The parameter of the proportion coefficient of C2-T1 tilt angle/C2-C7 lordotic angle was selected based on the scatter diagram of neck rotation in Fig. 4. This proportion coefficient clearly divided the results into possible or impossible for rotational ADL in the graph. This suggested that the proportion coefficient of the C2-T1 tilt angle/C2-C7 lordotic angle might reflect the relationship of the $\mathrm{C} 2-\mathrm{C} 7$ lordotic angle and the C2-T1 tilt angle in neck rotation, which explained the relationships of the cervical alignments and the alar ligament. To clarify the legitimacy of this parameter, further biomechanical studies using normal subjects or fresh cadavers are required.

This study has several limitations. The biggest limitations were the small study population and the short follow-up pe- riod. Furthermore, the present study did not examine the relationships between fixed neck position and neurological outcomes, such as the degree of neurological improvement or C5 nerve palsy ${ }^{29}$. A longer-term examination including neurological outcomes is necessary.

\section{Conclusions}

Comprehensive QOL was significantly related to neurological improvements and to poor cervical spine function after PDF. Most limitations of ADL after PDF were related to ADL involving neck rotation. There was no significant risk factor detected for postoperative inability to perform ADL involving neck extension or flexion. Significant risk factors for the postoperative limitations of ADL involving neck rotation were $\mathrm{C} 2-\mathrm{C} 7$ lordotic angle $\geq 6^{\circ}$ or proportion coefficient of the $\mathrm{C} 2-\mathrm{T} 1$ tilt angle/C2-C7 lordotic angle $\leq 1.8$. To avoid postoperative spinal cord pressure from the anterior aspect, such as in OPLL, it is considered necessary to acquire a $\mathrm{C} 2-\mathrm{C} 7$ lordotic angle greater than at least $0^{\circ}$.

Conflicts of Interest: The authors declare that there are no relevant conflicts of interest.

Author Contributions: Kazunari Takeuchi wrote and prepared the manuscript, and all the authors participated in the study design. All authors have read, reviewed, and approved the article.

\section{References}

1. Kawaguchi Y, Nakano M, Yasuda T, et al. More than 20 years follow-up after en bloc cervical laminoplasty. Spine. 2016;41(20): 1570-9.

2. Takeuchi K, Yokoyama T, Ono A, et al. Limitations of activities of daily living accompanying reduced neck mobility after cervical laminoplasty. Arch Orthop Trauma surg. 2007;127(6):475-80.

3. Fukui M, Chiba K, Kawakami M, et al. JOA Back Pain Evaluation Questionnaire (JOABPEQ)/JOA Cervical Myelopathy Evaluation Questionnaire (JOACMEQ). The report on the development of revised versions. April 16, 2007. The Subcommittee of the Clinical Outcome Committee of the Japanese Orthopaedic Association on Low Back Pain and Cervical Myelopathy Evaluation. J Orthop Sci. 2009;14(3):348-65.

4. Fehlings MG, Barry S, Kopjar B, et al. Anterior versus posterior surgical approaches to treat cervical spondylotic myelopathy: outcomes of the prospective multicenter AOSpine North America CSM study in 264 patients. Spine. 2013;38(26):2247-52.

5. Mehdi SK, Alentado VJ, Lee BS, et al. Comparison of clinical outcomes in decompression and fusion versus decompression only in patients with ossification of the posterior longitudinal ligament: a meta-analysis. Neurosurg Focus. 2016;40(6):E9.

6. Koda M, Mochizuki M, Konishi H, et al. Comparison of clinical outcomes between laminoplasty, posterior decompression with instrumented fusion, and anterior decompression with fusion for Kline (-) cervical ossification of the posterior longitudinal ligament. Eur Spine J. 2016;25(7):2294-301.

7. Takeuchi K, Yokoyama T, Numasawa T, et al. K-line (-) in the neck-flexed position in patients with ossification of the posterior longitudinal ligament is a risk factor for poor clinical outcome af- 
ter cervical laminoplasty. Spine. 2016;41(24):1891-5.

8. Chiba K, Toyama Y, Watanabe M, et al. Impact of longitudinal distance of the cervical spine on the results of expansive opendoor laminoplasty. Spine. 2000;25(22):2893-8.

9. Takeuchi K, Yokoyama T, Aburakawa S, et al. Axial symptoms after cervical laminoplasty with C3 laminectomy compared with conventional C3-C7 laminoplasty: a modified laminoplasty preserving the semispinalis cervicis inserted into axis. Spine. 2005;30 (22):2544-9.

10. Takeuchi K, Yokoyama T, Numasawa T, et al. A novel posterior approach preserving three muscles inserted at $\mathrm{C} 2$ in multilevel cervical posterior decompression and fusion using $\mathrm{C} 2$ pedicle screws. Eur Spine J. 2017 [Epub ahead of print].

11. Patwardhan AG, Khayatzadeh S, Nguyen NL, et al. Is cervical sagittal imbalance a risk factor for adjacent segment pathomechanics after multilevel fusion? Spine. 2016;41(10):E580-8.

12. Takeuchi K, Yokoyama T, Ono A, et al. Limitation of activities of daily living accompanying reduced neck mobility after laminoplasty preserving or reattaching the semispinalis cervicis into axis. Eur Spine J. 2008;17(3):415-20.

13. The EuroQol Group. EuroQol: a new facility for the measurement of health-related quality of life. Healthy Policy. 1990;16(3):199208.

14. Vanagas G. Receiver operating characteristic curves and comparison of cardiac surgery risk stratification systems. Interactive cardiovascular and thoracic surgery. 2004;3(2):319-22.

15. Daniels AH, Hart RA, Hilibrand AS, et al. Iatrogenic spinal cord injury resulting from cervical spine surgery. Global Spine J. 2017; 7(1 Suppl):84S-90S.

16. Song KJ, Choi bw, Lee DH, et al. Acute airway obstruction due to postoperative retropharyngeal hematoma after anterior cervical fusion: a retrospective analysis. J Orthop Surg Res. 2017;12(1):19.

17. Cole T, Veeravagu A, Zhang M, et al. Surgeon procedure volume and complication rates in anterior cervical discectomy and fusions: analysis of a national longitudinal database. Clin Spine Surg. 2017;30(5):E633-9.

18. Lau D, Chou D, Mummanen PV. Two-level corpectomy versus three-level discectomy for cervical spondylotic myelopathy: a comparison of postoperative, radiographic, and clinical outcomes. J Neurosurg Spine. 2015;23(3):280-9.

19. Perrone O, Tassi V, Mattioli B, et al. Pharyngo-esophageal perfo- ration following anterior cervical discectomy and fusion: management and results. Eur J Cardiothoracic Surg. 2017;51(1):160-8.

20. Rosenthal BD, Nair R, Hsu WK, et al. Dysphagia and dysphonia assessment tools after anterior cervical spine surgery. Clin Spine Surg. 2016;29(9):363-7.

21. Yoshihara H, Passias PG, Errico TJ. Screw-related complications in the subaxial cervical spine with the use of lateral mass versus cervical pedicle screws: a systematic review. J Neurosurg Spine. 2013;19(5):614-23.

22. Gelalis ID, Paschos NK, Pakos EE, et al. Accuracy of pedicle screw placement: a systematic review of prospective in vivo studies comparing free hand, fluoroscopy guidance and navigation techniques. Eur Spine J. 2012;21(2):247-55.

23. Theologis AA, Burch S. Safety and efficacy of reconstruction of complex cervical spine pathology using pedicle screws inserted with stealth navigation and 3D image-guided (O-arm) technology. Spine. 2015;40(18):1397-406.

24. Abumi K, Shono Y, Taneichi H, et al. Correction of cervical kyphosis using pedicle screw fixation systems. Spine. 1999;24(22): 2389-96.

25. Fujiyoshi T, Yamazaki M, Kawabe J, et al. A new concept for making decisions regarding the surgical approach for cervical ossification of the posterior longitudinal ligament: The K-line. Spine. 2008;33(26):E990-3.

26. Schroeder GD, Kepler CK, Kurd MF, et al. Is it necessary to extend a multilevel posterior cervical decompression and fusion to the upper thoracic spine? Spine. 2016;41(23):1845-9.

27. Panjabi MM, Yue JJ, Dvorak J, et al. The Cervical Spine, 4th ed. Philadelphia: Lippincott Williams \& Wilkins; 2005. Section I-4, Cervical spine kinematics and clinical instability; p. 55-78.

28. Cattrysse E, Barbero M, Kool P, et al. 3D morphometry of the transverse and alar ligaments in the occtipito-atlanto-axial complex: an in vitro analysis. Clin Anat. 2007;20(8):892-8.

29. Shiozaki T, Otsuka H, Nakata $Y$, et al. Spinal cord shift on magnetic resonance imaging at 24 hours after cervical laminoplasty. Spine. 2009;34(3):274-9.

Spine Surgery and Related Research is an Open Access journal distributed under the Creative Commons Attribution-NonCommercial-NoDerivatives 4.0 International License. To view the details of this license, please visit (https://creativeco mmons.org/licenses/by-nc-nd/4.0/). 